\title{
Capabilities of Additively Manufactured Rope Drums
}

\author{
Raimond Hofmann*, Christopher Matthes, Thorsten Schmidt \\ Chair of Assembly Technology for Textile Products, Institute of Textile Machinery and High Performance Material \\ Technology (ITM), Technische Universität Dresden, Germany \\ * Correspondence: raimond.hofmann@tu-dresden.de
}

Received 8 October 2020; Accepted 9 October 2020; Available online 7 December 2020

(C) 2020 by R. Hofmann et al. This is an open access article distributed under the Creative Commons Attribution License (CC-BY 4.0), which permits unrestricted use, distribution, and reproduction in any medium, provided the original work is properly cited.

\begin{abstract}
Many industry sectors benefit from the new opportunities additive manufacturing provides. Lightweight designs and integration of function are only two aspects. As there are no approaches present to insert additive manufacturing into the design of hoisting appliances though, we try to evaluate the room for improvement through experimental analysis. Additively manufactured synthetic drum-bodies fit for $8 \mathrm{~mm}$ wire ropes and containing different infill structures were tested for tensile strength. The cylindrical gyroid TPMS and straight spokes structures performed best with standardised tensile strengths of 17.53 and $16.40 \mathrm{kN} / \mathrm{kg}$. Our findings indicate that additively manufactured rope drums can be a viable option for future hoisting appliances.
\end{abstract}

KEYWORDS Additive manufacturing, hoisting appliances, drum winch, experimental analysis, wire rope, fused layer modeling, fused filament fabrication, fused deposition modeling, light weighting

\section{Introduction}

Additive manufacturing (AM) provides many advantages and initiates rapid changes in design and production in many engineering sectors. Intricate infill structures result in lightweight and still robust components. Triply periodic minimal surface (TPMS) structures for example follow designs from nature to form robust yet lightweight components [1]. AM also allows strong integration of function as it allows complex shapes that could not be manufactured conventionally [2,3]. Supply chains benefit from AM as well as it could reduce large storage capacities for products consisting of a high number of different parts. The used manufacturing machines (e.g. 3D printers) do not require long preparation times between the production of different components so production may be swapped quickly in relation to demand. During the covid-19 outbreak, the Italian AM company Isinova resupplied a hospital in Brescia with 3D-printed valves within hours. Those valves were used in livesaving ventilation devices and were not available from the usual supplier [4].

A growing research interest in AM machine parts leads to studies that directly investigate different components. For example, [5], [6], and [7] examine the properties of AM spur gears. Hoisting appliances, however, have not been a topic in academic discussion regarding the 
potential for improvement through AM components. In this work, we therefore do so by analysing an AM drum body. The drum body is a core component of every drum winch. It accounts for the biggest part of the rope drum's weight and possesses a rope groove that is challenging to manufacture. This means that it could benefit from two strengths of AM components, their low weight and their capability for integration of function through complex designs. Drum winches are widespread hoisting devices so any findings made may influence big industry sectors (e.g. logistics, construction). Our analysis consists of experiments that determine the tensile strength of drum body specimens with different infill structures. The cylindrical gyroid TPMS structure as well as the straight spokes structure present viable options for drum bodies regarding tensile strength. Additionally, the results were standardised on the specimens' weight as [8] and [9] imply a correlation between the infill structures weight and its tensile strength. This delivers a first glance on the weight of future drum bodies suited for different working loads.

\section{Methods}

Following, the choices regarding material, AM process, the specimens' design, and the experimental approach are explained.

\subsection{Choice of material}

AM can process many different materials from metals and ceramics to plastics and even paper. However, the two possible choices for an AM rope drum are metal and plastic, of which we chose the latter. At comparable infill rates, plastic AM-parts are even lighter than their metal counterparts are. Therefore, plastic rope-drums are more fit to demonstrate the weight-saving potential of AM components. Metal also requires more sophisticated manufacturing processes whereas plastic is easier to use with even simpler processes. The specific plastic for the specimen is Polylactic Acid (PLA). PLA is a highly usable plastic with decreased warping tendency and low melting temperature compared to other plastics, especially acrylonite butadiene styrene (ABS). PLA also is cost-efficient, biodegradable and can be processed through fused layer modelling. Disadvantages are its hydrophilic nature and low heat resistance. Its mechanical properties and heat resistance can improve after additional annealing [10]. As pigments influence the mechanical properties of PLA negatively, colourless PLA was used.

\subsection{Choice of AM process}

For our experiments, we chose the fused layer modelling (FLM) process - also named fused deposition modeling (FDM) or fused filament fabrication (FFF), which is commonly known from consumer-grade 3D printers (Figure 1a). Using FLM provides different advantages. It is a common manufacturing process with high usability, so satisfactory specimens can be created with a relatively low effort. Additionally, manufacturing costs are significantly lower than with e.g. selective laser sintering (SLS). 
All specimen were printed on an Ultimaker 3 (UM3) from Ultimaker BV with an AA 0.4 print core (Figure $1 \mathrm{~b}$ ). Its nozzle diameter is $0.4 \mathrm{~mm}$. Instead of the stock extruder we used the DDG-extruder from Bondtech AB. Except from the top due to the printer's design, the build volume is fully enclosed to minimize temperature and draft interference. All CAD-models were sliced in Ultimaker Cura 4.5.0. Table 1 shows the custom print settings we applied to the "normal $0.15 \mathrm{~mm}$ " template. The printing speed (outer wall speed, top/bottom speed, infill speed) was lower than usual at $45 \mathrm{~mm} / \mathrm{s}$ to improve bonding between adjacent layers. The initial printing speed was $15 \mathrm{~mm} / \mathrm{s}$ to improve the specimens' adhesion on the build plate. Z-Seam alignment was at a fixed-point to get the same starting point for each layer on each specimen. This allowed the identification of a re-occurring breaking point that may result due to the print settings. The layer height was higher than default to decrease print time. Infill density was $100 \%$ for all infill structures except regular gyroid TPMS as those were custom created outside of Cura. Only for said regular gyroid TPMS structure the infill density was adjusted to match the target weight as it was created directly in Cura.

The ambient temperature was measured at a constant $35^{\circ} \mathrm{C}$ during the printing process. [12] shows that the printing and heat bed temperature only divert little from the set values, hence measuring those was not necessary. Magigoo print adhesive was applied on the UM3's glass build-plate to improve adhesion and reduce warping. The specimens were not annealed after printing in order not to insert an additional interfering factor in our analysis.

a)

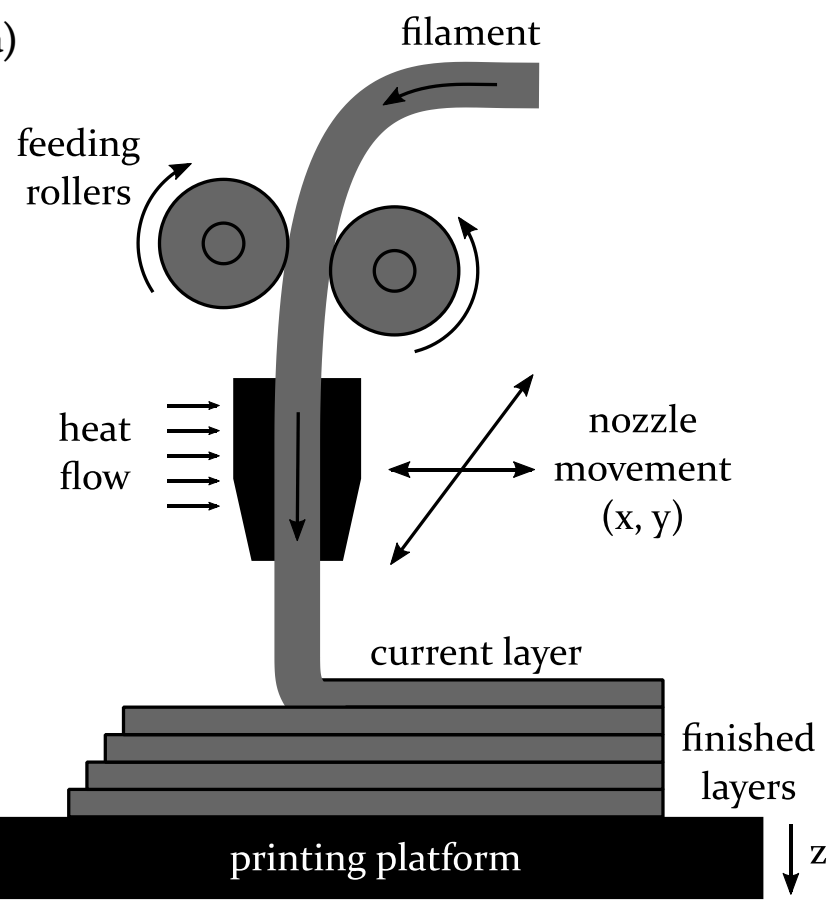

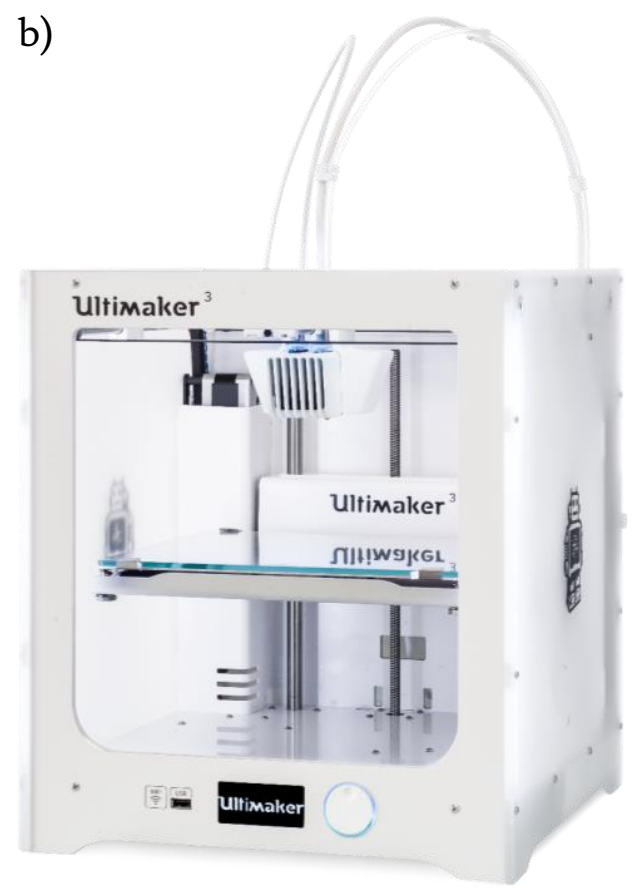

Figure 1: FLM process; a) schematic representation, b) FLM 3D-printer Ultimaker 3 [11] 
Table 1: Custom print settings

\begin{tabular}{ll}
\hline Parameter & Value \\
\hline Build plate adhesion type & skirt \\
Layer height & $0.2 \mathrm{~mm}$ \\
Initial layer height & $0.2 \mathrm{~mm}$ \\
Infill line width & $0.4 \mathrm{~mm}$ \\
Line width & $0.4 \mathrm{~mm}$ \\
Inner wall(s) line width & $0.4 \mathrm{~mm}$ \\
Extra skin wall count & 0 \\
Z-seam alignment & back \\
Wall line count & 10 \\
Outer wall speed & $45 \mathrm{~mm} / \mathrm{s}$ \\
Top/bottom speed & $45 \mathrm{~mm} / \mathrm{s}$ \\
Infill speed & $45 \mathrm{~mm} / \mathrm{s}$ \\
Initial layer speed & $15 \mathrm{~mm} / \mathrm{s}$ \\
Print speed & $60 \mathrm{~mm} / \mathrm{s}$ \\
Wall speed & $45 \mathrm{~mm} / \mathrm{s}$ \\
Infill pattern & lines \\
Infill density & $100 \%$ \\
Printing temperature & $215{ }^{\circ} \mathrm{C}$ \\
\hline
\end{tabular}

\subsection{Design of specimen}

Subject of our test is a drum body fit for $8 \mathrm{~mm}$ wire ropes (Figure 2). It resembles a drum body that is being used in a multi-layer spooling experiment for another research project. This provides the future opportunity to run spooling tests to obtain comparable data on the specimen fatigue behaviour. Table 2 displays its main dimensions. The drum body's outer diameter is $144 \mathrm{~mm}$; hence, the drum body is fits in the building space of common consumer FLM-printers. It is open from one side to allow inspection of the infill structure before and after the test run. The drum flanges are not subject of our investigation, as they do not experience any torsional stress like the drum body. Their weight is also considerably less than the drum body's. Therefore, the specimen does not include the drum flanges. An additional mounting plate, however, allows clamping a rope that will wrap around the drum and inserts a rope tension force into the drum body. To highlight the design capabilities of AM the drum body comes with a printed parallel-groove system. Such systems are superior to regular helical-groove systems in terms of rope durability but also are generally more expensive due to the more sophisticated manufacturing process. 

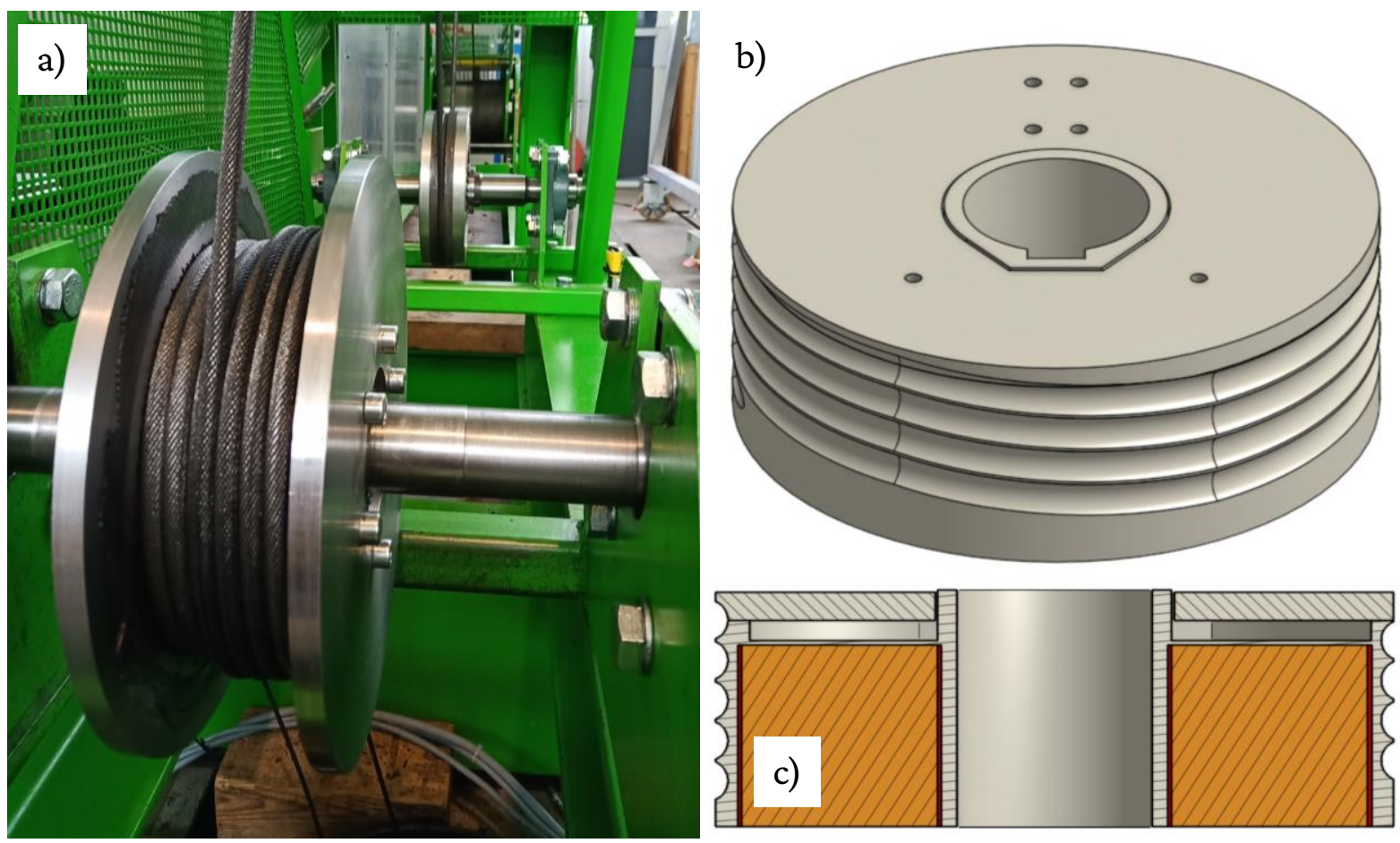

Figure 2: Specimen; a) rope drum in use in multi-layer spooling experiment, b) CAD image of specimen, c) section of specimen with infill volume (orange).

Table 2: Main dimensions of the specimen

\begin{tabular}{ll}
\hline Dimension & Value in $\mathbf{~ m m}$ \\
\hline Nominal diameter & 144 \\
Groove radius & 4 \\
Drum width & 50 \\
Hub diameter & 40 \\
\hline
\end{tabular}

Comparing different infill structures is subject of our analysis; hence, the specimens possess six different. Figure 3 shows the selection of infill structures. It contains TPMS structures (regular gyroid TPMS, cylindrical gyroid/diamond TPMS) but also other designs (spiral/straight spokes, helical-spiral lattice). This selection provides an ample overview over available infill structures rather than to dive into specific details. Except from the regular gyroid TPMS, which was created directly in Cura, all infill structures are axially symmetric. This is to take the anticipated torsional stress better. The other TPMS infill structures were created with nTopology's nTop, a special application for creating AM components. The remaining (spiral/straight spokes, helical-spiral lattice) infill structures were created with Onshape and refined in nTop as all edges were chamfered with a $3 \mathrm{~mm}$ radius. The specimens' target weight is $190 \pm 5 \mathrm{~g}$. This resembles roughly the feasible minimum for the FLM process as the goal is to demonstrate the utmost minimum of rope tensile force that an AM rope-drum this size can withstand. For future analyses, infill density may be increased to adjust to different mechanical requirements. 

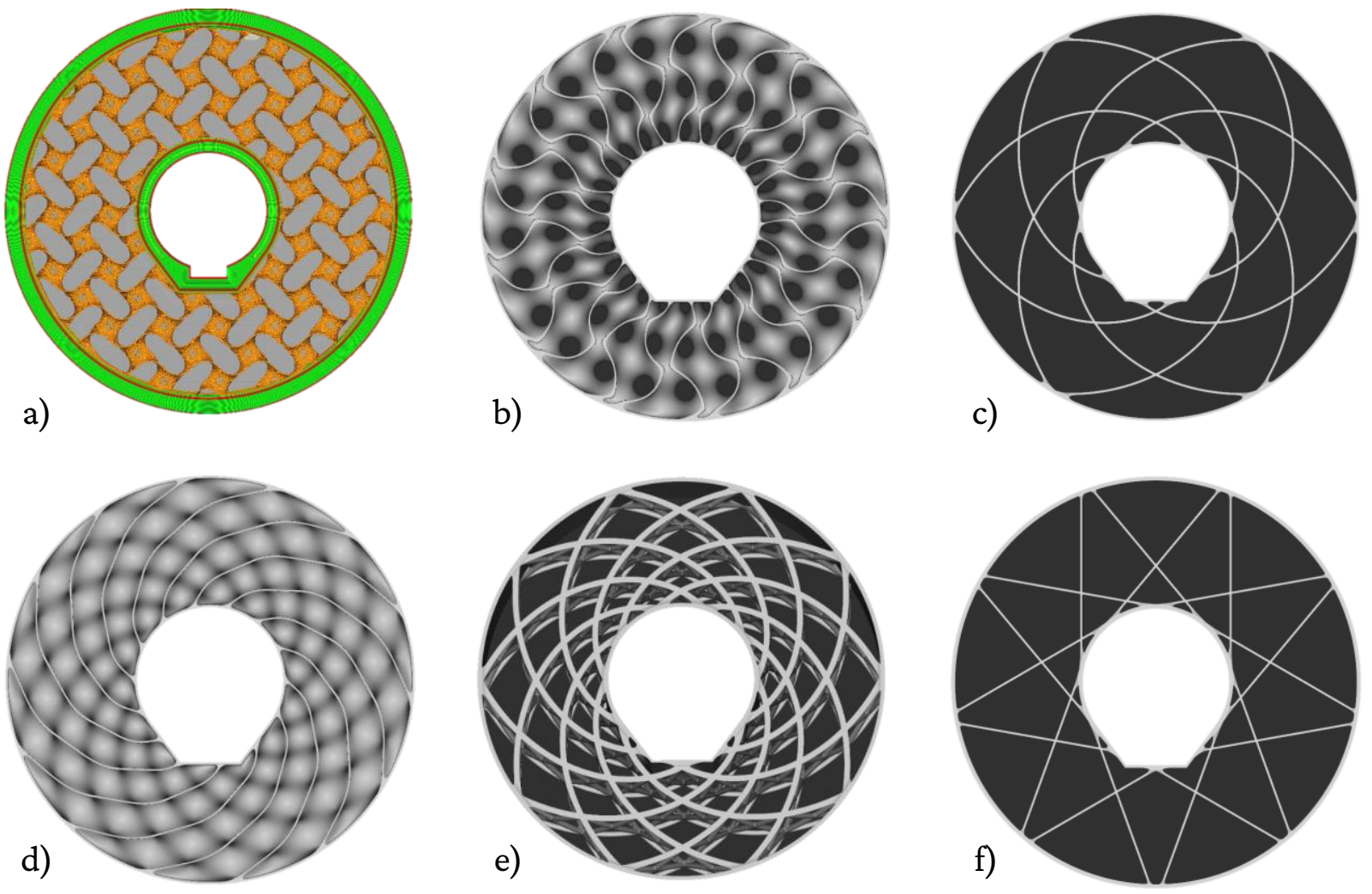

Figure 3: Chosen infill structures; a) regular gyroid TPMS, b) cylindrical gyroid TPMS, c) spiral spokes, d) cylindrical diamond TPMS, e) helical-spiral lattice, f) straight spokes

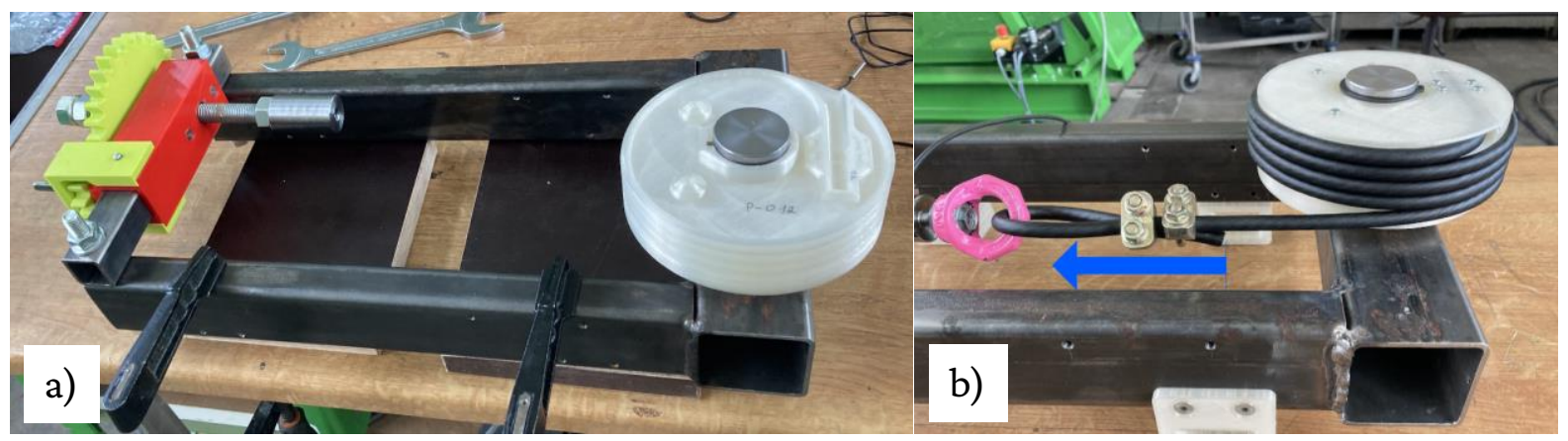

Figure 4: Test bench; a) general view, b) force insertion through rope

\subsection{Experimental approach}

The goal is to determine the maximum rope tension force that the different infill structures withstand. Figure 4 shows the test bench, which provides the ability to exert a rope tension force onto the specimen. For this, a short piece of rope wraps around the drum body to emulate real applications. The exerted rope tension force generates torsional stress inside the infill structure. A coated wire rope prevents damage to the groove, as this analysis is focused on the stability of the infill structure. A collapse due to damage to the outer surface and therefore the groove would interfere with any findings. The rope tension force builds up constantly through an electrically driven AM spur gear, which tightens the rope by adjusting a threaded rod. The specimen's collapse concluded the test run. To examine standard deviation and to get reliable data, five specimen were tested for each infill structure. The 
drum body's weight was noted for every specimen as well as the print time for every type of infill structure. The rope tension force was recorded versus time.

\section{Results}

Table 3 shows the specimens' print time for each infill structure. All infill structures except the regular gyroid TPMS and helical-spiral lattice result in similar print times around 16 hours. The latter increases print time by $50 \%$ to $23: 27$ hours. The regular gyroid TPMS results in the lowest print time of 14:03 hours.

Table 4 displays the specimens' weight by infill structure. It ranges from 180 to $190 \mathrm{~g}$ by average and from 180 to $196 \mathrm{~g}$ by total value. The average weight through all specimens is $187 \mathrm{~g}$ and therefore $3 \mathrm{~g}$ below the target weight of $190 \mathrm{~g}$, whereas the ratio of $\pm 5 \mathrm{~g}$ was met for each infill structure. The straight-spokes structure produced a considerably larger amplitude compared to the other infill structures. Figure 5 displays collapsed specimens after a test run. The degree of visible damage dealt to the specimen varies between the different infill structures, most notably between the TPMS (gyroid, cylindrical gyroid, cylindrical diamond), and the spokes (spiral, straight) and helical-spiral lattice structures. While the visible damage between those groups varies significantly, it is important to point out that the drop in rope tension force is similar for each infill structure.

Table 3: Specimens' print times for each infill structure.

\begin{tabular}{ll}
\hline Infill structure & Print time in hh:min \\
\hline Regular gyroid TPMS & $14: 03$ \\
Cylindrical gyroid TPMS & $16: 36$ \\
Spiral spokes & $15: 29$ \\
Cylindrical diamond TPMS & $16: 40$ \\
Helical-spiral lattice & $23: 27$ \\
Straight spokes & $16: 16$ \\
\hline
\end{tabular}

Table 4: Specimens' weight by infill structure.

\begin{tabular}{llllllll}
\hline Infill structure & & $\begin{array}{l}\text { Gyroid } \\
\text { TPMS }\end{array}$ & $\begin{array}{l}\text { Cylindrical } \\
\text { gyroid } \\
\text { TPMS }\end{array}$ & $\begin{array}{l}\text { Spiral } \\
\text { spokes }\end{array}$ & $\begin{array}{l}\text { Cylindrical } \\
\text { diamond } \\
\text { TPMS }\end{array}$ & $\begin{array}{l}\text { Helical- } \\
\text { spiral } \\
\text { lattice }\end{array}$ & $\begin{array}{l}\text { Straight } \\
\text { spokes }\end{array}$ \\
\hline Weight in g & Average & 190 & 183 & 183 & 183 & 189 & 193 \\
& Minimum & 190 & 183 & 182 & 180 & 189 & 187 \\
& $\begin{array}{l}\text { Maximum } \\
\text { Amplitude }\end{array}$ & 191 & 184 & 184 & 185 & 190 & 196 \\
& $\begin{array}{l}\text { Standard } \\
\text { deviation }\end{array}$ & 0.24 & 0.37 & 0.64 & 1.87 & 0.24 & 3.37 \\
& $\begin{array}{l}\text { Coefficient of } \\
\text { variation }\end{array}$ & $0.13 \%$ & $0.2 \%$ & $0.35 \%$ & $1.03 \%$ & $0.13 \%$ & $1.75 \%$ \\
\hline
\end{tabular}



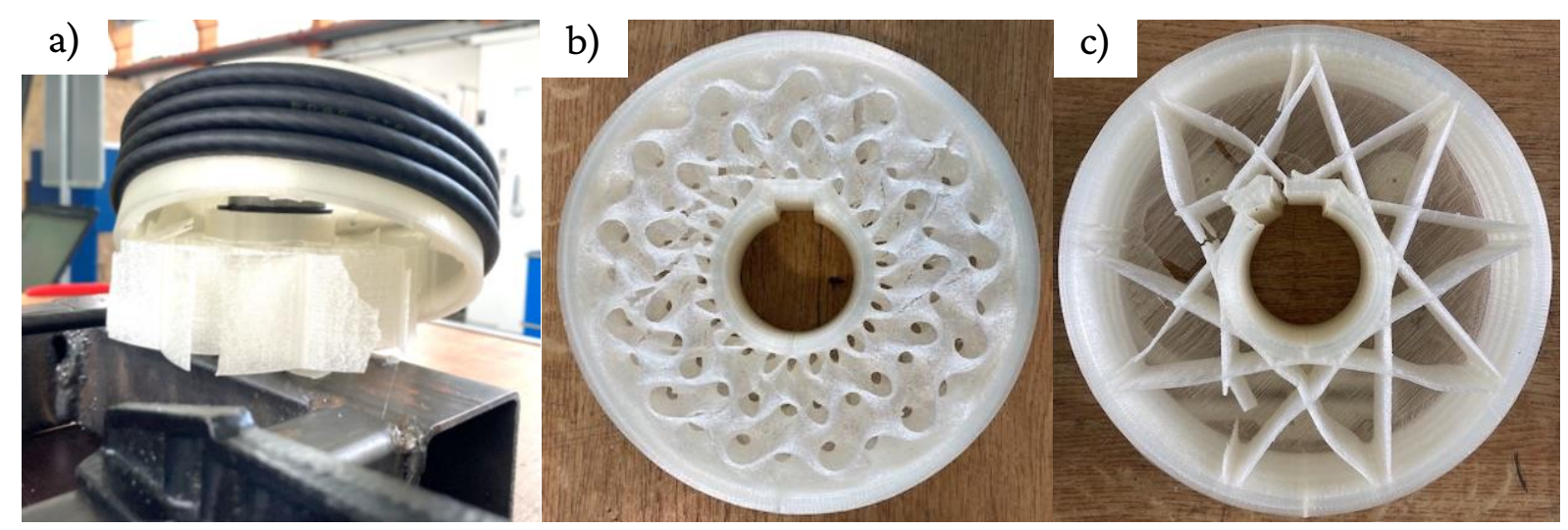

Figure 5: Collapsed specimens; a) on test bench after test run, b) cylindrical gyroid TPMS, c) straight spokes

a)

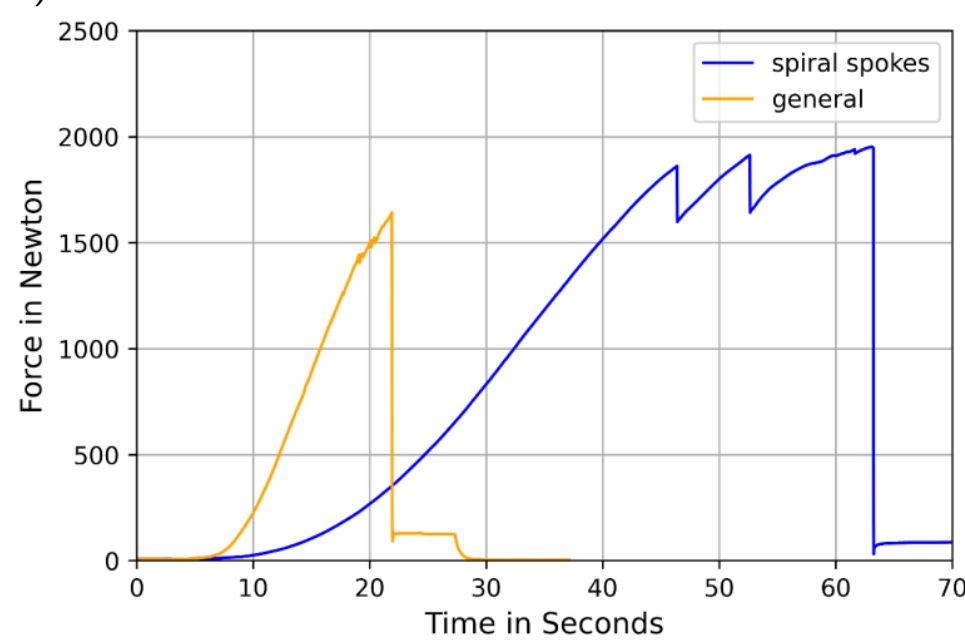

b)

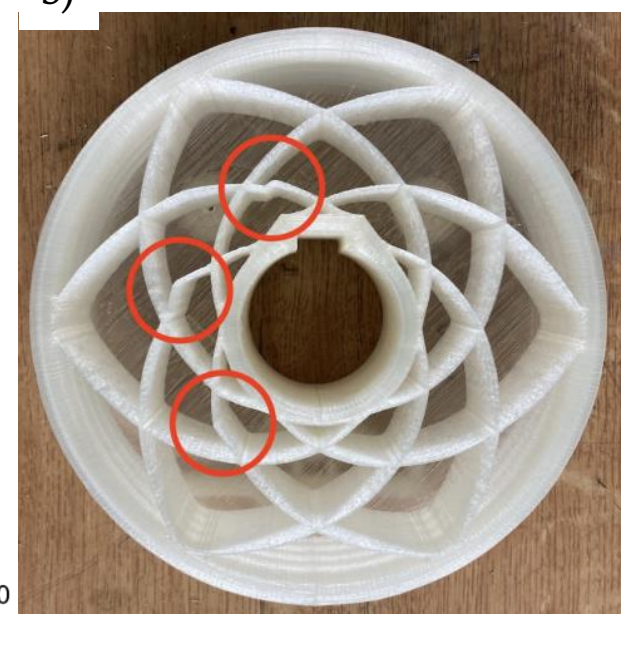

Figure 6: Collapse behaviour for different infill structures; a) characteristic force paths, b) Buckling on spiralspokes specimen

Figure 6a displays two characteristic force paths that occurred during the tensile tests. The first occurred with every infill structure except the spiral spokes. It shows a continuous rise that concludes in a singular peak when the specimen collapsed. The experiments with the spiral-spokes structure, however, produced multiple peaks prior to the specimen's collapse. Figure $6 \mathrm{~b}$ shows the collapsed spiral-spokes structure that resulted in the aforementioned force path. Three of the specimens' spiral spokes buckled under the experienced torsional load.

Table 5 contains the test results of the tensile tests. The cylindrical gyroid TPMS structure reaches the highest tensile strength with $3.22 \mathrm{kN}$ whereas cylindrical diamond TPMS $(2.95 \mathrm{kN})$ and the straight spokes $(3.17 \mathrm{kN})$ achieve similar values. The helical-spiral lattice structure scores lowest with $1.63 \mathrm{kN}$. The coefficient of variation ranges from 1.73 to $6.34 \%$. The order, in which the different infill structures performed, remains the same for the standardised tensile strength while the changes to the coefficient to variation are insignificant. The range for the tensile strength is 1.63 to $3.22 \mathrm{kN}$ and 17.53 to $8.61 \mathrm{kN} / \mathrm{g}$ for the standardised tensile strength. Again, cylindrical gyroid $(17.53 \mathrm{kN} / \mathrm{g})$ and diamond $(16.16 \mathrm{kN} / \mathrm{g})$ TPMS as well as the straight spokes $(16.40 \mathrm{kN} / \mathrm{g})$ achieve the highest values. 
Table 5: Summary of test results by infill structure.

\begin{tabular}{|c|c|c|c|c|c|c|c|}
\hline Infill structure & & $\begin{array}{l}\text { Gyroid } \\
\text { TPMS }\end{array}$ & $\begin{array}{l}\text { Cylindrical } \\
\text { gyroid TPMS }\end{array}$ & $\begin{array}{l}\text { Spiral } \\
\text { spokes }\end{array}$ & $\begin{array}{l}\text { Cylindrical } \\
\text { diamond } \\
\text { TPMS }\end{array}$ & $\begin{array}{l}\text { Helical } \\
\text { spiral } \\
\text { lattice }\end{array}$ & $\begin{array}{l}\text { Straight } \\
\text { spokes }\end{array}$ \\
\hline \multirow{3}{*}{$\begin{array}{l}\text { Tensile strength } \\
\text { in } \mathrm{kN}\end{array}$} & Average & 1.92 & 3.22 & 2.03 & 2.95 & 1.63 & 3.17 \\
\hline & $\begin{array}{l}\text { Standard } \\
\text { deviation }\end{array}$ & 0.03 & 0.90 & 0.06 & 0.19 & 0.05 & 0.14 \\
\hline & $\begin{array}{l}\text { Coefficient of } \\
\text { variation }\end{array}$ & $1,73 \%$ & $2,79 \%$ & $3,18 \%$ & $6,34 \%$ & $2,80 \%$ & $4,44 \%$ \\
\hline \multirow{3}{*}{$\begin{array}{l}\text { Standardised } \\
\text { tensile strength } \\
\text { in } \mathrm{kN} / \mathrm{kg}\end{array}$} & Average & 10,09 & 17,53 & 11,06 & 16,16 & 8,61 & 16,40 \\
\hline & $\begin{array}{l}\text { Standard } \\
\text { deviation }\end{array}$ & 0,18 & 0,47 & 0,33 & 0,89 & 0,24 & 0,47 \\
\hline & $\begin{array}{l}\text { Coefficient of } \\
\text { variation }\end{array}$ & $1,79 \%$ & $2,70 \%$ & $3,01 \%$ & $5,53 \%$ & $2,73 \%$ & $2,85 \%$ \\
\hline
\end{tabular}

\section{Discussion}

Our analysis shows that AM drum bodies could be an alternative for future hoisting appliances. They are able to provide a significant amount of tensile strength despite their low weight, which is the first step in harnessing the design capabilities of AM for future hoisting appliances.

The tested TPMS structures as well as the spokes structures, which are oriented more toward conventional design principles, produce one structure with a leading tensile strength of about $17 \mathrm{kN} / \mathrm{kg}$, in particular the cylindrical gyroid TPMS $(17.53 \mathrm{kN} / \mathrm{kg})$ and straight spokes $(16.40 \mathrm{kN} / \mathrm{kg})$ structures. This shows that both approaches to design are viable paths to create sufficient drum bodies solely regarding tensile strength. An interesting topic for future research would be to merge both structures to receive a hybrid that benefits from both designs' advantages.

Given that infill density and tensile strength most likely correlate according to previous studies, a first estimate for the weight of a practical drum body is possible. To match the minimum breaking force of a standard $8 \mathrm{~mm}$ lifting rope (ca. $50 \mathrm{kN}$, [10] [13]) an AM drum body with the standardised tensile strength of $17 \mathrm{kN} / \mathrm{kg}$ would weigh about $2.9 \mathrm{~kg}$. This estimate does not account for any other loads than the static rope tension force, however.

The translational gyroid TPMS structure produces an inferior tensile strength compared to its cylindrical counterpart, therefore infill structures for drum bodies should be oriented cylindrical.

Visible signs of the specimens' damage did not correlate with their actual damage. This foreshadows challenges regarding damage evaluation on actual products in use. A possible solution would be to manipulate the infill structure so that it shows premature signs of damage, much like the tested spiral spokes structure.

The significantly higher print time for the helical-spiral lattice structure may result from its lattice design. Between printing the structure's high amount of trusses, the filament has to be retracted to prevent plastic from dripping. This results in a higher amoung of retractions 
for the helical-spiral lattice structure compared to the other infill structures. On the other side, a cause for the short print time of the regular gyroid TPMS structure may be its creation in Cura, which is different from all other structures. This might result in the demonstrated print time as it was generated and sliced in one process, which facilitates further optimisation from Cura.

The planned amount of five test runs per infill structure was sufficient for the desired accuracy. Aside from a experimental point of view, this speaks for the reliability of FLM printed components for mass produced hoisting appliances.

To conclude, our analysis implicates that AM drum bodies of sufficient tensile strength are possible. Before they will be used in future hoisting appliances, however, several properties of such drum bodies have to be examined. Though highly likely, experimental proof of a correlation between infill density and tensile strength should quantify the exact relation between both parameters. Fatigue behaviour of such drum bodies should be tested under practical conditions to address potential safety issues over life time. Finally, how AM drum bodies affect the drive chain's dynamic behaviour poses an interesting question, too.

\section{References}

[1] Pelanconi, M. und Ortona, A.: Nature-Inspired, Ultra-Lightweight Structures with Gyroid Cores Produced by Additive Manufacturing and Reinforced by Unidirectional Carbon Fiber Ribs, in: Materials (Basel, Switzerland), 2019, 12(24). https://dx.doi.org/10.3390/ma12244134\#

[2] EOS GmbH: Funktionsintegration mit additiver Fertigung. https://www.eos.info/de/industrieller-3d-druck/vorteile/funktionsintegration (2020-00-05)

[3] Klahn, C., Leutenecker, B. und Meboldt, M.: Design Strategies for the Process of Additive Manufacturing, in: Procedia CIRP, 2015, 36, S. 230-235. https://dx.doi.org/10.1016/j.procir.2015.01.082\#

[4] Stepanek, M.: 3D-Drucker rettet Corona-Patienten in Italien das Leben. https://futurezone.at/produkte/3d-drucker-rettet-corona-patienten-in-italien-das-leben/400783262 (2020-00-05)

[5] Ramadani, R., Belsak, A., Kegl, M., Predan, J. und Pehan, S.: Topology Optimization Based Design of Lightweight and Low Vibration Gear Bodies, in: International Journal of Simulation Modelling, 2018, 17(1), S. 92-104. https://dx.doi.org/10.2507/IJSIMM17(1)419\#

[6] Ramadani, R., Kegl, M., Predan, J., Belsak, A. und Stanislav, P.: Influence of Cellular Lattice Body Structure on Gear Vibration Induced by Meshing, in: Strojniški vestnik - Journal of Mechanical Engineering, 2018, S. 611-620. https://dx.doi.org/10.5545/sv-jme.2018.5349\#

[7] Berger, U.: Aspects of accuracy and precision in the additive manufacturing of plastic gears, in: Virtual and Physical Prototyping, 2015, 10(2), S. 49-57. https://dx.doi.org/10.1080/17452759.2015.1026127\#

[8] Pandzic, A., Hodzic, D., Milovanovic, A.: Effect of Infill Type and Density on Tensile Properties of PLA Material for FDM Process, 2019

[9] Abueidda, D. W., Elhebeary, M., Shiang, C.-S., Pang, S., Abu Al-Rub, R.K. und Jasiuk, I.M.: Mechanical properties of 3D printed polymeric Gyroid cellular structures: Experimental and finite element study, in: MATERIALS \& DESIGN, 2019, 165, S. 107597. https://dx.doi.org/10.1016/j.matdes.2019.107597\#

[10] Wang, S., Daelemans, L., Fiorio, R., Gou, M., D’hooge, D.R., Clerck, K. de und Cardon, L.: Improving Mechanical Properties for Extrusion-Based Additive Manufacturing of Poly(Lactic Acid) by Annealing and Blending with Poly(3-Hydroxybutyrate), in: POLYMERS, 2019, 11(9). https://dx.doi.org/10.3390/polym11091529

[11] Ultimaker BV: Ultimaker 3 (2020-00-05) 
[12] Kuznetsov, V. E., Tavitov, A.G., Urzhumtsev, O.D., Mikhalin, M.V. und Moiseev, A.I.: Hardware Factors Influencing Strength of Parts Obtained by Fused Filament Fabrication, in: POLYMERS, 2019, 11(11). https://dx.doi.org/10.3390/polym11111870\#

[13] Casar Drahtseilwerk Saar GmbH: Casar Starlift, Kirkel, DE, 03.2019.

https://www.casar.de/Portals/0/Documents/Product-Specs/Starlift.pdf\# 